\title{
Admission Body Temperature in Critically III Patients as an Independent Risk Predictor for Overall Outcome
}

\author{
Ralf Erkens $^{a, b}$ Bernhard Wernly ${ }^{c}$ Maryna Masyuk ${ }^{a, b}$ Johanna M. Muessig ${ }^{a, b}$ \\ Marcus Franz $^{d}$ Paul Christian Schulze ${ }^{d}$ Michael Lichtenauer ${ }^{c}$ Malte Kelmª \\ Christian Jung a, b \\ a Division of Cardiology, Pulmonology and Vascular Medicine, Medical Faculty, Heinrich Heine University Düsseldorf, \\ Düsseldorf, Germany; ${ }^{\mathrm{b} C A R I D, C a r d i o v a s c u l a r ~ R e s e a r c h ~ I n s t i t u t e ~ D u ̈ s s e l d o r f, ~ M e d i c a l ~ F a c u l t y, ~ H e i n r i c h ~ H e i n e ~}$ \\ University Düsseldorf, Düsseldorf, Germany; ${ }^{C}$ Department of Cardiology, Clinic of Internal Medicine II, Paracelsus \\ Medical University of Salzburg, Salzburg, Austria; ${ }^{d}$ Department of Cardiology, Clinic of Internal Medicine I, Jena \\ University Hospital, Jena, Germany
}

\section{Significance of the Study}

- Estimating the outcome of intensive care unit (ICU) patients is difficult, whereas existing scores are often too complex. We assessed admission body temperature (BT) as an independent risk predictor for the individual outcome.

- Admission BT was associated with the adverse overall outcome.

- Hypothermia was more often associated with multi-organ failure than hyperthermia.

- Hypothermia is more often associated with increased mortality.

\section{Keywords}

Admission body temperature $\cdot$ Risk stratification · Risk predictor · Critically ill patients · Prognostication · Intensive care unit

\footnotetext{
Abstract

Introduction: Body temperature (BT) abnormalities are frequently observed in critically ill patients. We aimed to assess admission BT in a heterogeneous critically ill patient population admitted to an intensive care unit (ICU) as a prognostic parameter for intra-ICU and long-term mortality. Methods: A total of 6,514 medical patients ( $64 \pm 15$ years) admit-
}

ted to a German ICU between 2004 and 2009 were included. A follow-up of patients was performed retrospectively. The association of admission BT with both intra-ICU and longterm mortality was investigated by logistic regression. $\boldsymbol{R} \boldsymbol{e}$ sults: Patients with hypothermia $\left(<36^{\circ} \mathrm{C} \mathrm{BT}\right)$ were clinically worse and had more pronounced signs of multi-organ failure. Admission BT was associated with adverse overall outcome, with a 2-fold increase for hyperthermia (mortality $12 \%$; odds ratio [OR] 1.80, 95\% confidence interval [CI] 1.432.26; $p<0.001)$, and a 4-fold increase for the risk of hypothermia (mortality 24\%; OR 4.05, 95\% Cl 3.38-4.85; $p<0.001$ ) with respect to intra-ICU and long-term mortality. Moreover, hypothermia was even more harmful than hyperther-

\begin{tabular}{ll}
\hline KARGER & $\begin{array}{l}\text { ( } 2019 \text { The Author(s) } \\
\text { Published by S. Karger AG, Basel Oper }\end{array}$ \\
karger@karger.com & This is an Open Access article licensed under the Creative Commons \\
www.karger.com/mpp & $\begin{array}{l}\text { Attribution-NonCommercial-4.0 International License (CC BY-NC) } \\
\text { (http://www.karger.com/Services/OpenAccessLicense), applicable to } \\
\text { the online version of the article only. Usage and distribution for com- } \\
\text { mercial purposes requires written permission. }\end{array}$
\end{tabular}


mia, and both were strongly associated with intra-ICU mortality, especially in patients admitted with acute coronary syndrome (hypothermia: hazard ratio $6.12,95 \% \mathrm{Cl} 4.12-$ 9.11; $p<0.001$; hyperthermia: OR 2.70, 95\% Cl 1.52-4.79; $p<0.001)$. Conclusion: Admission BT is an independent risk predictor for both overall intra-ICU and long-term mortality in critically ill patients admitted to an ICU. Therefore, BT at admission might not only serve as a parameter for individual risk stratification but can also influence individual therapeutic decision-making.

(C) 2019 The Author(s)

Published by S. Karger AG, Basel

\section{Introduction}

Body temperature (BT) regulation is a complex variable, influenced by distinct internal and external factors. Its alteration in the setting of different diseases affects their progression and prognosis [1]. Normal BT for healthy adults $\left(\sim 37^{\circ} \mathrm{C}\right)$ is associated with proper organ function [2], whereas fever $\left(>38.5^{\circ} \mathrm{C}\right)$ is usually associated with the loss of physiological integrity [3] and contributes to host defense mechanisms during infections. In contrast to this, hypothermia $\left(<36^{\circ} \mathrm{C}\right)$ is thought to be associated with the dysregulation of thermoregulation and is often interpreted as an expression of disease exacerbation [4].

Dysregulation of BT is observed in nearly half of patients with a critical illness, and the association with adverse outcomes has already been identified. Therefore, a significant body of literature has investigated the influence of BT alterations, its modulation, and the prevention of its fluctuation during the stay at an intensive care unit (ICU), mostly in relation to the neurological outcome or for the estimation of overall mortality $[5,6]$. However, all these studies were performed to assess the impact of BT fluctuation on the overall outcome and did not focus on the impact of admission BT to the individual short-term (intra-ICU) and long-term mortality in critical illness [7]. Admittedly, they highlight the crucial importance of parameters possibly estimating individual prognosis but do not come up with an easily usable parameter for these important questions [8]. Of note, whilst 26 different functional measures have been described to use within critically ill patients in the ICU, only 6 of them have been developed specifically for the ICU setting [9]. Of them, only a few are used in daily practice, which is also due to their complexity in its calculation. In summary, these studies emphasize the urgent need for a safe and easy parameter to estimate the individual prognosis of critically ill patients.

Therefore, this study is an extension of the existing literature to facilitate the estimation of individual prognosis in critical illness and help optimize individual therapeutic decision-making in the early phase of intensive care treatment. It was designed to assess the prognostic value of a single $\mathrm{BT}$ assessment obtained at admission to predict the intra-ICU and overall long-term mortality, independently of admission diagnosis.

\section{Methods}

In total, 6,514 patients were admitted to the ICU of the Jena University Hospital between January 2004 and December 2009 because of sepsis $(n=565)$, acute heart failure (AHF; $n=630)$, pneumonia $(n=543)$, or acute coronary syndrome (ACS; $n=1,940)$ and were investigated retrospectively. Parts of this cohort were evaluated from a different perspective [10-12]. Inclusion criteria were admission to the medical ICU and a documented admission BT before an intensive care treatment was started. The exclusion criterion was status after successful cardiopulmonary resuscitation (with possible initiation of therapeutic hypothermia before ICU admission). Patients were separated into different groups based on the individual $\mathrm{BT}$ at admission to the ICU. Hypothermia was defined as a $\mathrm{BT}<36^{\circ} \mathrm{C}$, normal BT $36.1-37.5^{\circ} \mathrm{C}$, and hyperthermia as $\mathrm{BT}>37.5^{\circ} \mathrm{C}$. There was no prespecified treatment algorithm, neither in general nor with special regard to BT. Antipyretic medication and other temperature-managing measures were applied at the discretion of the treating physician.

The primary endpoint of the study was death due to any cause at discharge from ICU, and the secondary endpoint was long-term mortality ( 5 years). Data on mortality were collected by receiving medical records from our patient data management system (COPRA System GmbH, Germany) and/or phone interviews. All data were fully anonymized before evaluation. A minimal anonymized data set was made accessible without restrictions.

\section{Laboratory Analysis}

Blood samples were taken according to standard care. Laboratory parameters were obtained from the Department of Clinical Chemistry and Laboratory Medicine at the Jena University Hospital. Some laboratory values were measured repeatedly on the day of admission, and we report the maximum value unless stated differently.

\section{Measurement of BT}

At admission, BT was measured at baseline first at the left or right tympanic site (COVIDIEN Genius 2 Tympanic Thermometer). If necessary or already obtained, urine catheter placement was performed, and continuous BT was obtained (Philips IntelliVue).

\section{Calculation of Simplified Acute Physiology Score II}

Initial Simplified Acute Physiology Score II (SAPS2) was calculated by the treating physician within $24 \mathrm{~h}$ after admission as reported before [13]. 
Table 1. Clinical and laboratory baseline characteristics of the overall cohort and for each group of patients admitted to the ICU

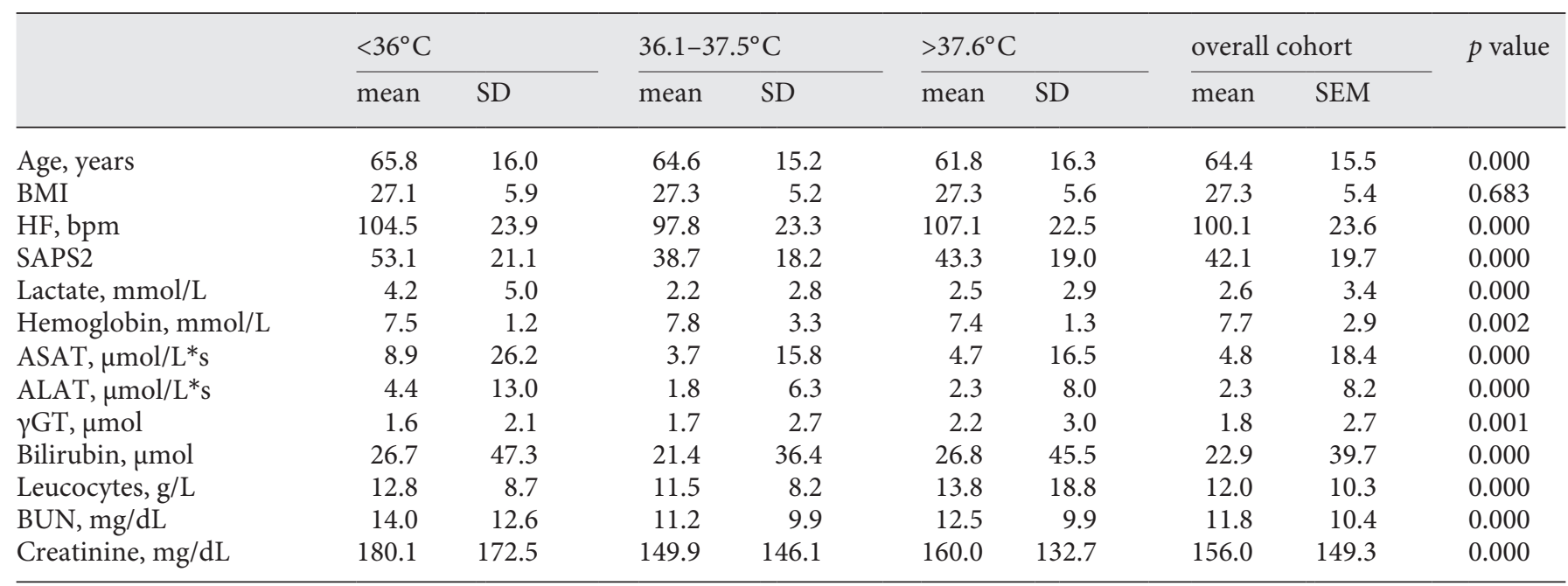

\section{Statistical Analysis}

Statistical analysis was performed using SPSS (IBM SPSS Statistics for Windows, Version 22.0; IBM Corp. Released 2013, Armonk, NY, USA) and MedCalc Software version 18.2.1 (MedCalc Software, Ostend, Belgium; https://www.medcalc.org; 2018). Continuous data are given as mean \pm standard deviation. Differences between independent groups were calculated using ANOVA. The $\chi^{2}$ test was applied to calculate differences between groups. Associations with intra-ICU mortality were assessed with univariable and multivariable logistic regression. Two multivariable models were analyzed: model 1 corrected for SAPS2, a well-known score assessing the risk in the critically ill; and model 2 corrected for parameters assessing shock (maximum heart rate on day 1, maximum lactate concentration on day 1 , and catecholamine use on day 1). For the multivariable model, a backward elimination was performed. Elimination criteria were $p>0.10$. The Kaplan-Meier curve was used to depict data on long-term survival, and differences in long-term survival were assessed using the log-rank test.

\section{Results}

\section{Study Subjects}

A total of 6,514 patients were investigated, and overall ICU mortality was $11 \%$. Out of these, 1,036 patients ( $16 \%)$ had a BT at admission of $<36^{\circ} \mathrm{C}, 4,617(71 \%)$ of $36.0-$ $37.5^{\circ} \mathrm{C}$, and 861 patients (13\%) had hyperthermia $\left(>37.5^{\circ} \mathrm{C}\right)$. Baseline characteristics are shown in Table 1 . Compared to normal temperature (mortality $7 \%$ ), both hypothermia (mortality $24 \%$; odds ratio [OR] $4.05,95 \%$ confidence interval [CI] 3.38-4.85; $p<0.001$ ) and hyperthermia (mortality 12\%; OR 1.80, 95\% CI 1.43-2.26; $p<$ $0.001)$ were associated with ICU mortality and long-term mortality (Fig. 1, log-rank $p<0.001$, Fig. 2).

Admission Body Temperature Predicts

Outcome for ICU Patients

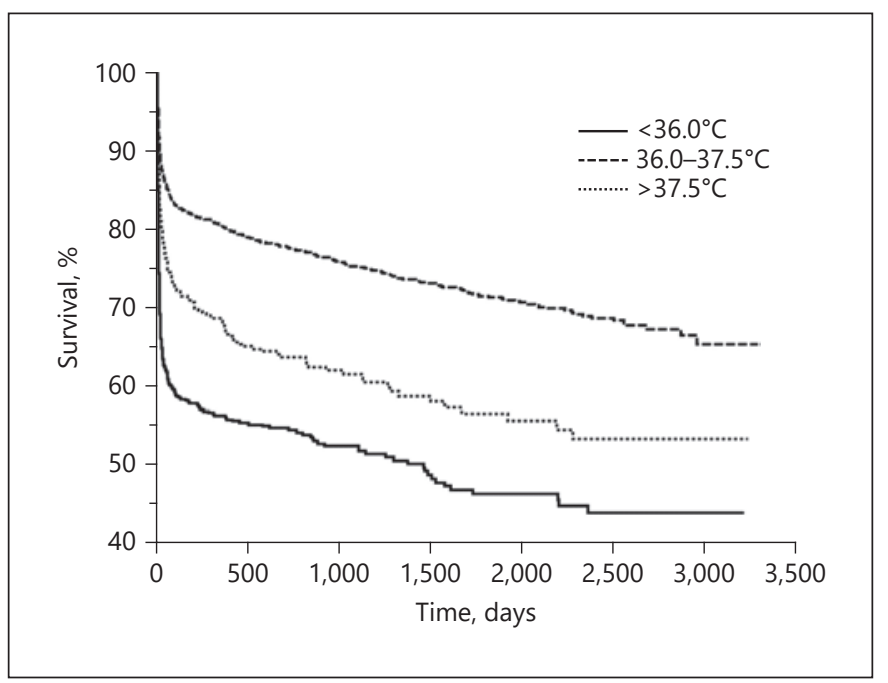

Fig. 1. In the overall population, alteration in BT on admission to the ICU was associated with adverse long-term outcome (log-rank $p<0.001)$.

\section{Hypothermia}

In multivariable logistic regression hypothermia compared to normal temperature was associated with allcause intra-ICU mortality after correction for SAPS II (OR 1.48, 95\% CI 1.12-1.96; $p=0.006$ ). In logistic regression for parameters that are associated with shock, such as lactate concentration, heart rate, and catecholamine use on day 1 , we found a significant increase in mortality (OR 1.86, 95\% CI 1.542-2.44; $p<0.001$, Table 2). Patients with an admission $\mathrm{BT}<36^{\circ} \mathrm{C}$ were clinically more ill as compared to patients admitted with normal BT, as mir- 
Table 2. Multivariable logistic regression analysis for hypothermia or hyperthermia for all-cause mortality corrected for SAPS2 and catecholamine use

\begin{tabular}{|c|c|c|c|c|c|c|c|}
\hline & \multicolumn{3}{|l|}{$<36^{\circ} \mathrm{C}$} & Normal BT & \multicolumn{3}{|l|}{$>37.5^{\circ} \mathrm{C}$} \\
\hline Mortality & $24 \%$ & & & $7 \%$ & $12 \%$ & & \\
\hline OR & 4.05 & 1.48 & 1.86 & & 1.8 & 1.39 & 1.27 \\
\hline $95 \%$ CI & $3.38-4.85$ & $1.12-1.96$ & $1.54-2.44$ & & $1.43-2.26$ & $1.00-1.95$ & $0.92-1.75$ \\
\hline
\end{tabular}

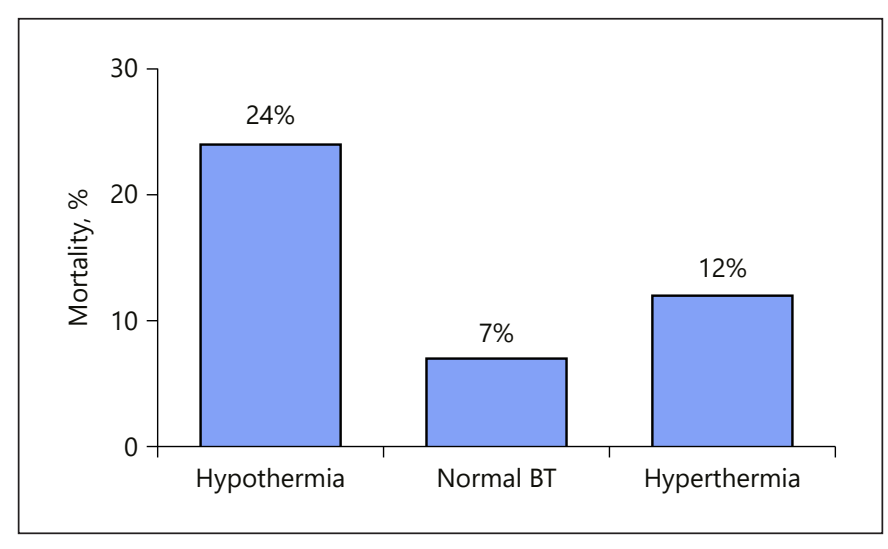

Fig. 2. In the overall population, alteration in BT on admission to the ICU was associated with adverse intra-ICU mortality.

rored by both higher SAPS2 $(p<0.001)$ and APACHE2 $(p<0.001)$. Hypothermia showed a "dose-response"; in logistic regression, per $1{ }^{\circ} \mathrm{C}$ less than $36.0^{\circ} \mathrm{C}$ (hypother$\mathrm{mia}=36.0-\mathrm{BT})$, the likelihood for mortality increased (OR 1.94, 95\% CI 1.63-2.31; $p<0.001$, Fig. 3). Hypothermia was associated with intra-ICU mortality in ACS (hazard ratio [HR] 6.12, 95\% CI 4.12-9.11; $p<0.001)$, sepsis (HR 2.34, 95\% CI 1.49-3.70; $p<0.001$ ), AHF (HR 2.79, 95\% CI 1.80-4.31; $<<0.001$ ), and pneumonia (HR 2.35, 95\% CI 1.39-3.96; $p=0.001)$.

\section{Hyperthermia}

Compared to the overall cohort, patients with fever at admission showed more pronounced hypoperfusion expressed by a higher lactate concentration $(p<0.0001)$ as well as a pronounced immune response as expressed by a higher leucocyte count $(p<0.001)$. Mortality for the hyperthermia group showed a "dose-response" to BT deterioration at admission in univariable logistic regression; per every degree Celsius $>37.5^{\circ} \mathrm{C}$ (hyperthermia $=\mathrm{BT}-$
37.5), the likelihood for ICU mortality increased (OR 1.82, 95\% CI 1.40-2.38; $p<0.001$; Fig. 3). In multivariable logistic regression analysis, hyperthermia remained associated with all-cause mortality even after correcting for SAPS2 (OR 1.39, 95\% CI 1.00-1.95; $p=0.053$ ), but not after correction for lactate concentration or heart rate and catecholamine use (OR 1.27, 95\% CI 0.92-1.75; $p=0.14$, Table 2). However, patients with a BT $>38.5^{\circ} \mathrm{C}(n=180)$ evidenced higher ICU mortality (19\%) even after correction for SAPS2 (OR 1.89, 95\% CI 1.04-3.44: $p=0.04$ ) as well as lactate concentration, heart rate, and catecholamine use (OR 1.88, 95\% CI 1.09-3.25; $p=0.02$ ).

Hyperthermia was associated with intra-ICU mortality in ACS (OR 2.70, 95\% CI 1.52-4.79; $p<0.001)$, but not in sepsis (OR 0.95, 95\% CI 0.63-1.41; $p=0.95$ ), pneumonia (OR $1.09,95 \%$ CI $0.68-1.76 ; p=0.71$ ), or AHF (OR $0.74,95 \%$ CI $0.38-1.47 ; p=0.40$ ).

\section{Discussion}

This study demonstrates that the single measurement of BT at admission to ICU is useful to predict the individual outcome, especially for the prognosis of intra-ICU mortality. Each deviation of $1{ }^{\circ} \mathrm{C}$ from normal BT at admission, regardless of whether decrease or increase, is associated with an increase in individual mortality that was evidenced by the likelihood analysis for intra-ICU mortality. Unexpectedly, hypothermia was associated with an increase in intra-ICU mortality in a multivariable and univariable logistic regression analysis, even after correction for lactate levels, which can be used as a prognostic parameter for ICU patients. Furthermore, our results show that hypothermia at disease exacerbation is a strong predictor of adverse outcome in sepsis, AHF, pneumonia, and ACS patients, whereas hyperthermia was associated 
Fig. 3. With any deviation from normal temperature, all-cause mortality shows a relevant increase (likelihood analysis: hypothermia: OR 1.94, 95\% CI 1.63-2.31; $p<$ 0.001 ; hyperthermia: OR $1.82,95 \% \mathrm{CI}$ $1.40-2.38 ; p<0.001)$.

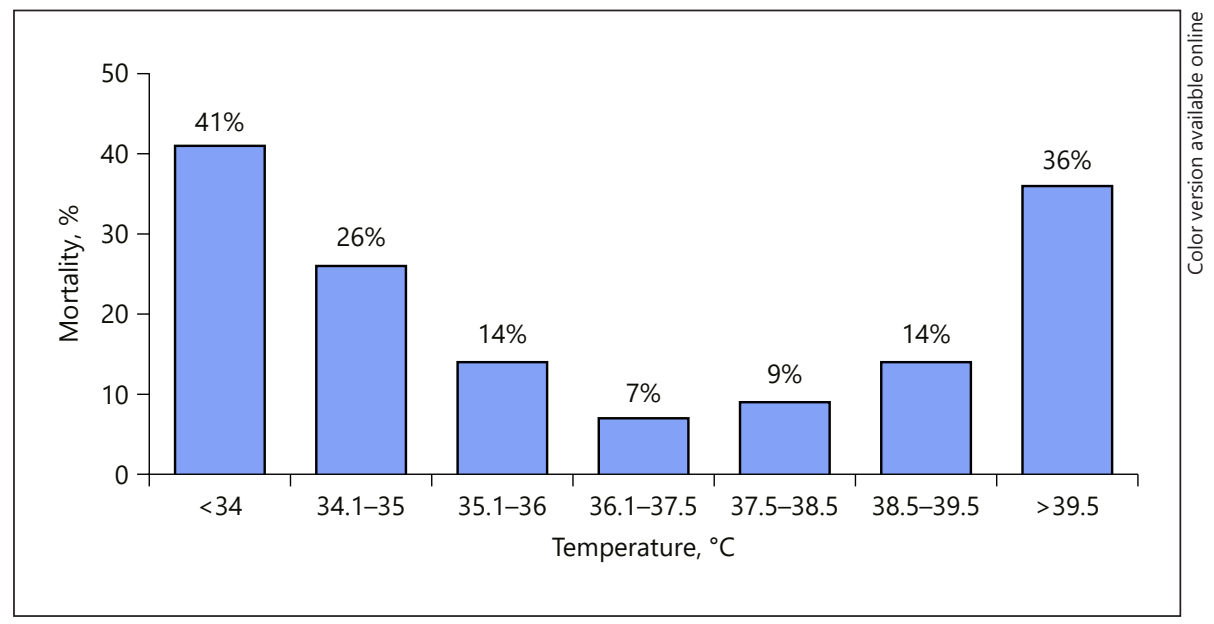

only with adverse outcome in ACS patients. Additionally, the occurrence of hypothermia was associated with an increase in catecholamine use during the first day of ICU treatment, as an expression of hemodynamic depression of disease exacerbation. This is in line with the significant association in a multivariable logistic regression analysis of SAPS II even after correction for lactate.

Temperature dysregulation is common among patients who have critical illness, and admission BT is included in risk stratification parameters such as SAPS2 or APACHE2 (higher or lower temperature) $[13,14]$. The impact of BT abnormalities (especially fever and hypothermia) for neurological outcome in patients after cardiopulmonary resuscitation $[5,15]$ or the impact of BT alteration in trauma patients [16] has been investigated. However, most of these studies focus on the relevance of modulating thermoregulation (actively or passively [6]) during the stay $[4,17]$ in the ICU and did not indicate any significance of admission BT to patient prognosis. Therefore, the present study is an important addition to the existing literature, demonstrating the relevance of $\mathrm{BT}$ at admission for the overall outcome and identifying the impact of this easy parameter for intra-ICU and long-term mortality prediction. We showed that hypothermia and hyperthermia at admission were significantly associated with an elevated SAPS2 score as compared to those with normal BT.

Interestingly, every deviation of $1^{\circ} \mathrm{C}$ less than normal BT was associated with elevated lactate levels and increased mortality. These findings could be interpreted as evidence for the disability of sicker patients in preserving the thermoregulation system [18] and helps in the interpretation of the clinical status; even hemodynamic mon-

Admission Body Temperature Predicts

Outcome for ICU Patients itoring indicates a seemingly compensated situation. Keeping this in mind, one might also not expect the frequency of hypothermia at admission to be more common, which may be interpreted as a result of disease exacerbation with adverse outcome. This was also highlighted by the fact that hypothermia was associated with an increase in catecholamine requirements to ensure hemodynamic stability on the first day of ICU treatment. Of note, we cannot identify the mechanism of hypothermia development, which also may be influenced by hemodynamic shock, previous drug therapy, or insufficient thermoregulation, especially in ACS or sepsis patients. Dysregulation of the thermoregulatory system and decrease in BT is known to be co-influenced by systemic hemodynamic depression, which favors this condition [19]. Therefore, our results support this hypothesis by the fact that hypothermia was found to be related to an increase in catecholamine use on day 1 in the ICU, which was also associated with an increase in mortality in a multivariable logistic regression analysis. However, the exacerbation of some diseases (e.g., sepsis and pneumonia) results in the dysregulation of hypothalamic BT regulatory pathways, which supports the occurrence of hypothermia and the association with a 2.3 -fold increase in intra-ICU mortality for patients with sepsis. Indeed, this is in line with other observational trials $[20,21]$ and data from national databases, suggesting an increase in mortality in patients with extremes of temperature (especially $<36{ }^{\circ} \mathrm{C}$ and $>39.1{ }^{\circ} \mathrm{C}$ ) [22]. Of note, we cannot identify the mechanism of why the host response to infection is impaired by preexisting hypothermia or fever. However, these observations may be explained by physical exhaustion related to BT changes, cumulative stress and therefore an im- 
paired immunological response [23] or other confounding factors influencing thermoregulation such as previous drug therapy or progressive endocrine diseases. Nevertheless, we confirm these observations especially for the intra-ICU outcome. This is of special interest because most of the previous studies deal with the treatment and relevance of elevated BT and do not focus on the impact of hypothermia as an influencing factor for mortality, specifically in sepsis $[24,25]$. Hence, it was demonstrated that fever predicts a lower mortality rate and shorter hospital stay in patients with septic shock admitted to the ICU [26], which is in line with our results, highlighting no significant association of hyperthermia and intra-ICU mortality in a univariable logistic regression model corrected for sepsis.

Contrary to this, BT dysregulation is common for decompensation of $\mathrm{HF}$ and used as a predictor of worse outcomes [27]. We confirm this phenomenon of hypothermia to be associated with adverse outcomes for intra-ICU mortality and complement the current state of knowledge: in our analysis, hyperthermia $\left(>37.5^{\circ} \mathrm{C}\right)$ has no adverse effect on mortality in decompensated HF. On the contrary, experts are divided on the therapeutic need to intervene when BT is elevated and whether hyperthermia might be useful and protective in some settings of critical illness [28]. Recently, it has been shown that less fever management in an all-comers population of critically ill patients was correlated with a decrease in mortality as compared to more active fever management. Our results confirm the observation that hyperthermia in the overall cohort is associated with a lower mortality rate as compared to the hypothermia group [29].

The continuous monitoring of BT during the stay at an ICU is normal practice, and the relevance of BT alteration for acute and future [30] cardiovascular outcome has been recently described. Interestingly, our results indicate that the one-time measurement of admission BT can also be used as an early and independent predictor for intra-ICU mortality in ACS, AHF, sepsis, and pneumonia patients. These results are an important extension of the common doctrine that focuses only on hypothermia and accepts fever as a symptom of associated diseases. Studies to assess the relevance of BT modulation for disease morbidity are required.

Limitations of this study include the fact that it was conducted in a single center and that it was retrospective in nature. Moreover, there were no data available on the pathogenesis of sepsis/AHF/pneumonia/ACS in our patients and the cause of death. Patients were treated according to the treating physician's decisions following in- ternational guidelines, but we have no data about specific antibiotic regimens. We have no specific data about BT regulation after admission to the ICU nor any data about medication influencing BT prior to admission. Furthermore, BT measurement was performed based on the admission workflow either on the left or right tympanic side and not on the same side of each patient. Of note, BT alterations may have more than one potential cause in ICU patients, and we did not distinguish other reasons notwithstanding those that we have mentioned. Despite these limitations, we believe that our study emphasizes the importance of admission BT for the overall mortality and identifies this parameter as an independent value of ICU patient outcome. One should take into account that hypothermia is sometimes used as a therapeutic target to improve neurological outcomes; e.g., after successful cardiopulmonary resuscitation, and that the prevention of fever and therapeutic strategies to normalize BT were not considered in this study.

\section{Conclusions}

Our observations indicate that BT at admission is highly relevant and independently associated with the overall intra-ICU and long-term survival. Patients with hypothermia or hyperthermia have a significant increase in mortality compared to normothermic patients, independent of admission diagnosis. Interestingly, hypothermia seems to be a relevant and independent prognostic parameter for increased intra-ICU and long-term mortality. This highlights the importance of BT on ICU admission for individual prognostication and therefore might be used in individual treatment decision-making.

\section{Statement of Ethics}

The study was approved by the local Ethics Committee of the Medical Faculty of the Friedrich Schiller University of Jena and waived the requirement for written consent.

\section{Disclosure Statement}

The authors have completed and returned the ICMJE Form for Disclosure of Potential Conflicts of Interest. This work was supported by the Forschungskommission of the Medical Faculty of the Heinrich Heine University Düsseldorf (No. 2018-50, to Ralf Erkens) for a Clinician Scientist Track. All other authors report no conflicts of interest regarding the content herein. 


\section{References}

1 Laupland KB. Fever in the critically ill medical patient. Crit Care Med. 2009 Jul;37(7 Suppl):S273-8.

2 Wunderlich CA. Medical Thermometry and Human Temperature. New York: William Wood \& Company; 1871.

3 Kramer MR, Vandijk J, Rosin AJ. Mortality in elderly patients with thermoregulatory failure. Arch Intern Med. 1989 Jul;149(7):15213.

4 Peres Bota D, Lopes Ferreira F, Mélot C, Vincent JL. Body temperature alterations in the critically ill. Intensive Care Med. 2004 May; 30(5):811-6.

5 den Hartog AW, de Pont AC, Robillard LB, Binnekade JM, Schultz MJ, Horn J. Spontaneous hypothermia on intensive care unit admission is a predictor of unfavorable neurological outcome in patients after resuscitation: an observational cohort study. Crit Care. 2010;14(3):R121.

6 Nakajima Y. Controversies in the temperature management of critically ill patients. J Anesth. 2016 Oct;30(5):873-83.

7 Laupland KB, Shahpori R, Kirkpatrick AW, Ross T, Gregson DB, Stelfox HT. Occurrence and outcome of fever in critically ill adults. Crit Care Med. 2008 May;36(5):1531-5.

8 Kaplan V, Angus DC. Surviving intensive care. Crit Care Med. 2002 Mar;30(3):703-5.

9 Parry SM, Granger CL, Berney S, Jones J, Beach L, El-Ansary D, et al. Assessment of impairment and activity limitations in the critically ill: a systematic review of measurement instruments and their clinimetric properties. Intensive Care Med. 2015 May;41(5):744-62.

10 Lichtenauer M, Wernly B, Ohnewein B, Franz M, Kabisch B, Muessig J, et al. The Lactate/ Albumin Ratio: A Valuable Tool for Risk Stratification in Septic Patients Admitted to ICU. Int J Mol Sci. 2017 Sep;18(9):18.

11 Wernly B, Lichtenauer M, Franz M, Kabisch B, Muessig J, Masyuk M, et al. Model for Endstage Liver Disease excluding INR (MELDXI) score in critically ill patients: easily available and of prognostic relevance. PLoS One. 2017 Feb;12(2):e0170987.
12 Masyuk M, Wernly B, Jung C. Prognostic relevance of serum lactate kinetics: a powerful predictor but not Chuck Norris in Intensive Care Medicine. Intensive Care Med. 2019 Aug;45(8):1174-5.

13 Le Gall JR, Lemeshow S, Saulnier F. A new Simplified Acute Physiology Score (SAPS II) based on a European/North American multicenter study. JAMA. 1993 Dec;270(24):295763.

14 Moreno RP, Metnitz PG, Almeida E, Jordan B, Bauer P, Campos RA, et al.; SAPS 3 Investigators. SAPS 3-From evaluation of the patient to evaluation of the intensive care unit. Part 2: development of a prognostic model for hospital mortality at ICU admission. Intensive Care Med. 2005 Oct;31(10):1345-55.

15 Ruborg R, Gunnarsson K, Ström JO. Predictors of post-stroke body temperature elevation. BMC Neurol. 2017 Dec;17(1):218.

16 Faizi M, Farrier AJ, Venkatesan M, Thomas C, Uzoigwe CE, Balasubramanian S, et al. Is body temperature an independent predictor of mortality in hip fracture patients? Injury. 2014 Dec;45(12):1942-5.

17 Laupland KB, Zahar JR, Adrie C, Schwebel C, Goldgran-Toledano D, Azoulay E, et al. Determinants of temperature abnormalities and influence on outcome of critical illness. Crit Care Med. 2012 Jan;40(1):145-51.

18 Romanovsky AA. Thermoregulation: some concepts have changed. Functional architecture of the thermoregulatory system. Am J Physiol Regul Integr Comp Physiol. 2007 Jan; 292(1):R37-46.

19 Goetzenich A, Schroth SC, Emmig U, Autschbach R, Pieske B, Rossaint R, et al. Hypothermia exerts negative inotropy in human atrial preparations: in vitro-comparison to rabbit myocardium. J Cardiovasc Surg (Torino). 2009 Apr;50(2):239-45.

20 Brivet F, Carras PM, Dormont J, Guidet B, Of fenstadt G, Gachot B, et al. Hypothermia, a pertinent clinical prognostic factor in severe systemic inflammatory response syndrome. Crit Care Med. 1994 Mar;22(3):533-4.
21 Remick DG, Xioa H: Hypothermia and sepsis. Front Biosci. 2006 Jan;11:1006-13.

22 Young PJ, Saxena M. Fever management in intensive care patients with infections. Crit Care. 2014 Mar; 18(2):206.

23 Cheshire WP Jr. Thermoregulatory disorders and illness related to heat and cold stress. Auton Neurosci. 2016 Apr;196:91-104.

24 Clemmer TP, Fisher CJ Jr, Bone RC, Slotman GJ, Metz CA, Thomas FO; The Methylprednisolone Severe Sepsis Study Group. Hypothermia in the sepsis syndrome and clinical outcome. Crit Care Med. 1992 Oct;20(10): 1395-401.

25 Theilen H, Ragaller M: [Therapy of hyperthermia in sepsis and septic shock. Necessary or injurious?]. Anaesthesist. 2007 Sep;56(9): 949-52, 954-6.

26 Sundén-Cullberg J, Rylance R, Svefors J, Norrby-Teglund A, Björk J, Inghammar M. Fever in the Emergency Department Predicts Survival of Patients With Severe Sepsis and Septic Shock Admitted to the ICU. Crit Care Med. 2017 Apr;45(4):591-9.

27 Payvar S, Spertus JA, Miller AB, Casscells SW, Pang PS, Zannad F, et al.; Efficacy of Vasopressin Antagonism in Heart Failure Outcome Study with Tolvaptan (EVEREST) Investigators. Association of low body temperature and poor outcomes in patients admitted with worsening heart failure: a substudy of the Efficacy of Vasopressin Antagonism in Heart Failure Outcome Study with Tolvaptan (EVEREST) trial. Eur J Heart Fail. 2013 Dec;15(12):1382-9.

28 Young PJ, Prescott HC. When less is more in the active management of elevated body temperature of ICU patients. Intensive Care Med. 2019 Sep;45(9):1275-8.

29 Young PJ, Bellomo R, Bernard GR, Niven DJ, Schortgen F, Saxena M, et al. Fever control in critically ill adults. An individual patient data meta-analysis of randomised controlled trials. Intensive Care Med. 2019 Apr;45(4):468-76.

30 Kawashima C, Matsuzawa Y, Akiyama E, Konishi M, Suzuki H, Hashiba K, et al. Prolonged Fever After ST-Segment Elevation Myocardial Infarction and Long-Term Cardiac Outcomes. J Am Heart Assoc. 2017 Jul;6(7):6. 